\title{
Evolutionary persistence in Gunnera and the contribution of southern plant groups to the tropical Andes biodiversity hotspot
}

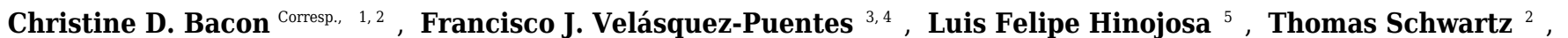
Bengt Oxelman $^{2}{ }^{\text {, Bernard Pfeil }}{ }^{2}$, Mary T. K. Arroyo ${ }^{5}$, Livia Wanntorp ${ }^{6}$, Alexandre Antonelli ${ }^{1,2,7}$

${ }^{1}$ Gothenburg Global Biodiversity Centre, Gothenburg, Sweden

3 Laboratório de Biología Molecular (CINBIN), Universidad Industrial de Santander, Bucaramanga, Colombia

4 Departamento de Química y Biología, Universidad del Norte, Barranquilla, Colombia

5 Institute of Ecology and Biodiversity, Facultad de Ciencias, Universidad de Chile, Santiago, Chile

6 Department of Phanerogamic Botany, Swedish Museum for Natural History, Stockholm, Sweden

7 Gothenburg Botanical Garden, Gothenburg, Sweden

Corresponding Author: Christine D. Bacon

Email address: christine.bacon@bioenv.gu.se

Several studies have demonstrated the contribution of northern immigrants to the flora of the tropical Andes - the world's richest and most diverse biodiversity hotspot. However, much less is known about the biogeographic history and diversification of Andean groups with southern origins, although it has been suggested that northern and southern groups have contributed roughly equally to the high Andean (i.e. páramo) flora. Here we infer the evolutionary history of the southern hemisphere plant genus Gunnera, a lineage with a rich fossil history and an important ecological role as an early colonising species characteristic of wet, montane environments. Our results show striking contrasts in species diversification, where some species may have persisted for some 90 million years, whereas others date to less than $2 \mathrm{Ma}$ since origination. The outstanding longevity of the group is likely linked to a high degree of niche conservatism across its highly disjunct range, whereby Gunnera tracks damp and boggy soils in cool habitats. Colonisation of the northern Andes is related to Quaternary climate change, with subsequent rapid diversification appearing to be driven by their ability to take advantage of environmental opportunities. This study demonstrates the composite origin of a mega-diverse biota. 


\section{Title}

2 Evolutionary persistence in Gunnera and the contribution of southern plant groups to the tropical

3 Andes biodiversity hotspot

\section{Authors}

6 Christine D. Bacon ${ }^{\mathrm{a}, \mathrm{b} *}$, Francisco J. Velásquez-Puentes ${ }^{\mathrm{c}, \mathrm{d}}$, Luis F. Hinojosa ${ }^{\mathrm{e}}$, Thomas Schwartz ${ }^{\mathrm{a}}$,

7 Bengt Oxelman ${ }^{\mathrm{a}, \mathrm{b}}$, Bernard Pfeil ${ }^{\mathrm{a}, \mathrm{b}}$, Mary T. K. Arroyo ${ }^{\mathrm{e}}$, Livia Wanntorp ${ }^{\mathrm{f}}$, Alexandre

8 Antonellia,b,g

\section{Author institutions}

11 aDepartment of Biological and Environmental Sciences, University of Gothenburg, Carl

12 Skottsbergs gata 22B, SE - 41319 Göteborg, Sweden

13 bGothenburg Global Biodiversity Centre, Box 461, SE-405 30 Gothenburg, Sweden

14 'Laboratório de Biología Molecular (CINBIN), Department of Biology, Universidad Industrial

15 de Santander, Bucaramanga, Colombia

16 dDepartamento de Química y Biología, Universidad del Norte, Barranquilla, Colombia

17 e'Institute of Ecology and Biodiversity, Facultad de Ciencias, Universidad de Chile, Casilla 653,

18 Santiago, Chile

19 fDepartment of Phanerogamic Botany, Swedish Museum of Natural History, Box 50007, SE -

2010405 Stockholm, Sweden

21 gGothenburg Botanical Garden, Carl Skottsbergs gata 22A, SE - 41319 Göteborg, Sweden 


\section{Corresponding authors $(*)$}

25 christinedbacon@gmail.com

26

\section{Running title}

28 Gunnera: diversification and persistence 


\section{Abstract}

30 Several studies have demonstrated the contribution of northern immigrants to the flora of the

31 tropical Andes - the world's richest and most diverse biodiversity hotspot. However, much less

32 is known about the biogeographic history and diversification of Andean groups with southern

33 origins, although it has been suggested that northern and southern groups have contributed

34 roughly equally to the high Andean (i.e. páramo) flora. Here we infer the evolutionary history of

35 the southern hemisphere plant genus Gunnera, a lineage with a rich fossil history and an

36 important ecological role as an early colonising species characteristic of wet, montane

37 environments. Our results show striking contrasts in species diversification, where some species

38 may have persisted for some 90 million years, whereas others date to less than 2 Ma since

39 origination. The outstanding longevity of the group is likely linked to a high degree of niche

40 conservatism across its highly disjunct range, whereby Gunnera tracks damp and boggy soils in

41 cool habitats. Colonisation of the northern Andes is related to Quaternary climate change, with

42 subsequent rapid diversification appearing to be driven by their ability to take advantage of

43 environmental opportunities. This study demonstrates the composite origin of a mega-diverse

44 biota. 


\section{1. Introduction}

Among the 34 biodiversity hotspots currently recognized, the tropical Andes is the richest and most diverse, comprising some 30,000 plant species [1]. This equates to nearly a tenth of the world's flora contained in less than one per cent of its land area. The tropical Andean hotspot, which stretches from western Venezuela to northern Chile and Argentina, constitutes an ideal arena for investigating the role of historical migrations in generating the exceptional plant species diversity found in the American tropics (the Neotropics). major role for in situ diversification, e.g. in Amazonia [e.g. 4, 5, but see 6] and the Andes [7, 8].

61 The relative contribution of immigrant lineages to modern Neotropical diversity is less understood, but has certainly played an important role [9]. For example, northern immigrants contributed more to the species diversity of the high elevation Andean páramo than southern immigrants [e.g. 10]. The contribution of immigrant taxa to modern Neotropical diversity may be primarily explained by either continuous range expansions from neighboring regions or longdistance dispersal, both from what today are temperate lineages into tropical latitudes (often facilitated by climatic change and mountain building), and from other trans-oceanic tropical regions [11]. Modern distributions reflect ancestral ecological requirements [niche conservatism; 12], but they also are affected by biome shifts, such as adaptation of cool temperate immigrants into cold tropical areas [13]. More rarely, migration events can also be directly associated with

71 physiological adaptations intro new environments $[14,15]$.

$$
\text { One of the characteristic elements of the Andes is the plant genus Gunnera (Gunneraceae; }
$$

73 Fig. S1). Although eleven Gunnera species are reported in the páramo [16], most of these are 
74 found in montane forests and only one is a strict páramo species, G. magellanica - which is also

75 found in the southern temperate Andes in wet habitats both below and above treeline [10].

76 Gunnera has been present in montane forests since at least the Middle Pliocene in Colombia

77 [17]. In comparison to páramo species from southern regions, fewer montane forest species, such

78 as Gunnera, have successfully colonised the northern Andes [18].

79 Gunnera includes 58 species primarily of the Southern Hemisphere (Africa, New Zealand,

80 South America, and Tasmania), but also reaches Hawaii, Mexico, and Southeast Asia [Fig. 1;

81 Table S1; 19, 20]. Despite this wide geographical distribution encompassing all southern

82 continents apart from Antarctica, the majority of extant species of Gunnera (up to 40 species in

83 subgenus Panke) are distributed in Central and South America [20], most of them within the

84 northern Andean biodiversity hotspot. However, Gunnera had an even wider geographic

85 distribution during the Cretaceous, as demonstrated by numerous fossil pollen records from the

86 Antarctic Peninsula, Australia, the Kerguelen Plateau, as well as in both North and South

87 America [21]. The oldest of these dates to the Turonian (ca. $90 \mathrm{Ma}$ ) of Peru [22] and ten million

88 years later Gunnera became widespread across all landmasses that previously formed Gondwana

89 [21]. Initial evidence suggested that biogeographic patterns in Gunnera are in agreement with the

90 sequence of Gondwanan break-up, prompting Wanntorp and Wanntorp (2003) to suggest a

91 Gondwanan origin for the genus and vicariance by continental drift as a plausible hypothesis to

92 explain the present-day distribution of most species in the genus. However, these conclusions

93 involved neither formal ancestral area reconstruction nor molecular dating. The study also did

94 not explicitly investigate the biogeographical history of the Andean species comprising subgenus

95 Panke. 
The current widespread distribution of Gunnera, its rich fossil record and the many still

97 unanswered questions regarding its biogeographic history all make Gunnera an ideal target for

98 investigating the role of southern immigrants in the assembly of the flora of the Andean

99 biodiversity hotspot. Here we infer the biogeographic, climatic, and evolutionary history of

100 Gunnera to explicitly address the following questions: Where did Gunnera most likely originate?

101 How and when did it attain its current distribution? When did it colonise the northern Andes

102 where it is most diverse? Are areas of high diversity in the genus associated with higher rates of

103 net diversification, or is diversity instead due to gradual accumulation of species? To what extent

104 have species of Gunnera tracked the ancestral climatic niche? We also compare Gunnera with

105 other Andean groups. Our study sheds further light on the geographical and temporal origins and

106 composition of the highly diverse Andean flora.

107

108 2. Material and methods

109

\section{0 (a) Phylogeny and divergence time estimation}

111 Taxon sampling was complete at the species level for five of six subgenera of Gunnera (27 out

112 of 58 species, ca. $46 \%$ ). Within subgenus Panke we could only obtain material for 14 of the up to

11340 species, because many species are only known from few collections or localities, hence the

114 difficulty in defining the exact number of species [20]. New DNA sequence data was generated

115 following the respective author protocols for the chloroplast regions $r p s 16$ [23], rpoC1 and $y c f 5$

116 from the Plant Working Group (www.kew.org/barcoding), psbA-trnH [24], as well as the nuclear

117 genes ITS [25] and SEX4 [26]. All new sequences generated in this study have been deposited in

118 GenBank (Appendix 1). Nucleotide alignments were obtained independently for each of the loci 
119 using default parameters for MUSCLE in Geneious (Biomatters, New Zealand). Due to poor

120 alignability, the ITS sequences of G. herteri and G. perpensa were removed. We used the Akaike

121 Information Criterion implemented in MrModelTest 2.2 [27] to select the best-fitting nucleotide

122 substitution model(s) and incorporated it in the inference of the species tree.

123 We used STACEY 1.04 (see http://www.indriid.com/software.html) in BEAST 2.3.0 and the

124 DISSECT method [28] to infer a multispecies coalescent tree. The method uses a version of the

125 birth/death branching model for the species tree, which assigns high probabilities for branching

126 events close to time zero; how close is defined by the "collapse height" parameter, which should

127 be set as small as possible [see 28]. The approach thus enables simultaneous exploration of

128 species tree and species delimitation space. Individuals or groups of individuals known to belong

129 to the same single species are operationally defined as minimal species. Clusters below the

130 collapse height are considered to belong to the same species, as defined by the multispecies

131 coalescent model. Here we defined all sequences from the same individual as minimal species. A

132 lognormal (mean 4.6, standard deviation 2) growth rate prior distribution was used for the

133 species tree. The growth rate is roughly 1 divided by the branch length, so that $95 \%$ of the

134 distribution falls within the interval $[2,5000]$ with median $e^{4.6} \approx 100$. Beta priors with shape

135 parameters 1, 1 (resulting in uniform distributions) were used on collapse weight and relative

136 death rates. A lognormal $(-7,2)$ prior was used for popPriorScale, which should approximate the

137 average time to coalescence between two gene copies. In order to scale branch lengths in

138 substitutions per site, the ITS rate was set to 1 and $\operatorname{lognormal}(0,1)$ priors for the relative rates of

139 the cpDNA and SEX4 trees were used. Collapse height was set to 0.0001 . Ploidy was set to 1 for

140 cpDNA and 2 for the two nuclear genes. The substitution model was GTR with a gamma prior

141 distribution $(0.05,10)$ on each substitution type, with rate variation among sites was modeled 
142 with four rate categories for all three loci. Each locus also had branch rates constrained to an

143 uncorrelated lognormal clock. The MCMC was run for 100 million generations and all

144 parameters had effective sample sizes $>180$ after removing the first 10 million generations as

145 burn-in. The maximum clade credibility species tree was generated by sampling trees every

$14650,000^{\text {th }}$ generation in the stationary phase (the last 90 million generations), where the heights

147 are common ancestor heights, scaled in substitutions/site.

148 A fossil Gunnera pollen grain was used to calibrate the phylogeny. Tricolpites reticulatus

149 from the Turonian of Peru [22] represents the first unambiguous appearance of the genus. Based

150 on this calibration point, the Turonian/Coniacian boundary (Late Cretaceous) was used to

151 provide a crown age of Gunnera by scaling the root of the STACEY tree (see above) using a

152 mean age of $90 \mathrm{Ma}$. Its placement on the crown of Gunnera is based on a morphological review

153 of extant and fossil pollen of Gunnera species, as assessed with scanning electron microscopy to

154 define morphological characters of the exine and its structure to support its placement on the 155 topology [29].

157 (b) Biogeographic analyses

158 Distribution data were compiled from Mora-Osejo et al. [20] and Wanntorp and Wanntorp [18]

159 together with records from the Global Biodiversity Information Facility (www.gbif.org) and

160 regional herbaria (CONC and MEL) that were vetted by the authors. Using the extant

161 distribution of Gunnera we defined nine operational areas for ancestral area estimation (Fig. 2):

162 (A) northern Andes, from Venezuela and Colombia to northernmost Peru, corresponding to the

163 páramos north of the Huancabamba Depression; (B) central Andes, from northern Peru (south of

164 the Huancabamba Depression) south to the Tropic of Capricorn and including the Altiplano, 
165 Jalca, and Puna; (C) southern Andes, from northern Chile south to Patagonia, including the

166 islands off the coasts of Chile and Argentina; (D) southeastern South America, including the

167 lowlands of southeastern Brazil and the Rio Paraná drainage; (E) Mesoamerica, from southern

168 Mexico to southernmost Panama; (F) the Hawaiian islands; (G) Africa, including Madagascar;

169 (H) the Malay archipelago, including New Guinea; (I) Tasmania and New Zealand.

170 We inferred ancestral biogeographic ranges using the package BioGeoBEARS 0.2.1 [30]

171 in the R platform [R Core 31]. BioGeoBEARS implements widely used models of range

172 evolution [e.g. 32], but it includes an additional parameter of cladogenetic speciation mediated

173 by founder events: the jump parameter “ $\mathrm{j}$ ". This parameter allows daughter species to

174 instantaneously "jump" outside the geographical range of parental species. We considered this

175 model appropriate since several Gunnera species occur on oceanic islands (e.g., the Hawaiian

176 and Juan Fernandez Islands). We inferred ancestral ranges across the Gunnera phylogeny using

177 the Dispersal Extinction Cladogenesis (DEC) model with the J parameter $(+\mathrm{j})$. The among-area

178 connectivity was constrained in the following time slices as follows: northern and central

179 Andean co-distributions were not permitted before $40 \mathrm{Ma}$ [33, 34], Hawaiian distributions were

180 not permitted before $30 \mathrm{Ma}$ [35], lower connectivity ( 0.1 rate of dispersal) was set between

181 Africa and South America throughout the last $90 \mathrm{Ma}$, as well as between South America and

182 New Zealand plus Tasmania throughout the last $30 \mathrm{Ma}$ [36] (Table S2).

183

184 (c) Diversification rate analysis

185 To test for diversification rate shifts we used the software BAMM 2.0 [Bayesian Analysis of

186 Macroevolutionary Mixtures; 37]. BAMM implements a Bayesian framework to estimate

187 evolutionary rate parameters and explore candidate models of lineage diversification to quantify

188 and detect heterogeneity in evolutionary rates. We ran BAMM using default priors for 1,000,000 
189 generations sampling every 20 steps and accounting for incomplete taxon sampling. We analysed

190 the output in R using the BAMMtools package 2.0.2 [37]. We discarded the first 25\% estimates

191 as burn-in based on the convergence of our data (effective sampling size of parameters greater

192 than 200). We generated plots of net diversification and speciation rates through time and

193 inferred the occurrence and position of rate shifts accounting for the 95\% HPD of BAMM-

194 inferred rate shifts based on a Bayes factor cut-off of 5.

\section{6 (d) Climatic niche evolution}

197 We performed ecological niche modeling for all 27 species of Gunnera included in the

198 phylogenetic analysis using Maxent [38] with 8 WorldClim bioclimatic variables at a resolution

199 of approximately $1 \mathrm{~km}^{2}$ [39], following the methodology of Evans et al. [40]. The bioclimatic

200 variables associated with temperature were: Mean annual temperature (MAT), minimum

201 temperature of coldest month (MTCM), mean temperature of warmest quarter (MTWQ), and

202 mean temperature of coldest quarter (MTCQ). Bioclimatic variables associated with precipitation

203 were: Mean annual precipitation (MAP), precipitation of wettest quarter (PWETQ), precipitation

204 of driest quarter (PDQ), and precipitation of warmest quarter (PWARMQ). Climatic variables

205 were chosen because of their biological meaning and by removal of the other 11 correlated

206 WorldClim variables after a principal components analysis. We used a total of 882 vetted species

207 occurrence points [see (b) above]. From the ecological niche models we obtained the mean value

208 for each of the eight bioclimatic variables weighted by the cumulative probability of each value

209 (weighted mean; wmean) to be used in comparative analyses, using the R package phyloclim

210 [41]. To infer the climatic history of Gunnera, we used the projection of our phylogenetic tree in 
211 environmental (each bioclimatic variable) and temporal space assuming Brownian motion

212 evolution [BM; 40, 42], using the R package phytools [43].

213 Phylogenetic niche conservatism (PNC), defined as the retention of ecological traits, each

214 bioclimatic variable (wmean values), over time among related species [12], was estimated using

215 Pagel's lambda [44] in the R package GEIGER [42]. Lambda ranges from one when trait

216 evolution is strongly influenced by phylogeny, and a species niche-to-phylogeny correlation is

217 equal to the Brownian model expectation, to zero when trait evolution is independent of

218 phylogeny [45]. We used a likelihood ratio test [46] to determine whether the observed values

219 differed significantly from zero and one. In general, phylogenetic signal indicates a statistical

220 non-independence among species trait values due to relatedness, consistent with PNC [12]. To

221 examine PNC explicitly we used the Akaike Information Criterion (wAIC) to compare the

222 relative fit of three models of evolution to each bioclimatic variable (wmean values). The models

223 include i) a Brownian motion (BM) model of gradual and continuous drift, ii) a stabilizing

224 selection Ornstein-Uhlenbeck (OU) model with one optimum; and iii) a white noise (WN)

225 model of random variation, in which the similarity of species is independent of their

226 phylogenetic relationships [47]. We performed this comparison using GEIGER. The

227 phylogenetic dependence of the realized climatic variation between related species, combined

228 with the comparison of BM, OU, and WN models, provides an assessment for testing PNC

229 (Losos, 2008; Wiens et al., 2010) and was thus suitable for our study. 
232 3. Results

233

234 (a) Multispecies coalescent tree

235 The multispecies coalescent tree reconstructed here is consistent with the topology of the

236 maximum parsimony tree based on molecular and morphological data of Wanntorp and

237 Wanntorp (2003). All major clades were resolved with moderate to high support $(>0.80$

238 posterior probabilities; Fig. 2), but some recent species-level relationships received poor branch 239 support.

240 Wide time intervals (95\% highest posterior density, HPD, values) were inferred for early

241 nodes on the phylogeny (Nodes I and III, Fig. 2) but more recent nodes had little variation

242 around the mean inferred age (e.g. Nodes VI and VII, Fig. 2). Overall the crown node of

243 Gunnera was inferred at a mean age of $90 \mathrm{Ma}$ (95\% HPD 165 - $40 \mathrm{Ma})$. Following the origin

244 and diversification of the genus in the Late Cretaceous, the two major clades of Gunnera

245 originated between 31 (46 - 17 Ma, Node III, Fig. 2) and $10 \mathrm{Ma}$ (15 - 5 Ma, Node II, Fig. 2).

246 Contrasting results were resolved with regard to the time of origin of species, where Gunnera

247 herteri had a mean age of $90 \mathrm{Ma}$ and many others, particularly the Andean species, are younger 248 than 2 Ma (Fig. 2)

249

250 (b) Biogeographic and diversification history

251 The BioGeoBEARS analysis resulted in broadly distributed ancestral nodes at the backbone of

252 the tree, reflected in the uncertainty in ancestral range (distributions with $<5 \%$ probability of

253 occurrence combined are the white portions in pie charts; Fig. 2). Despite this, internal nodes ca. 
$25412 \mathrm{Ma}$ and younger were inferred with less ambiguity in ancestral area. These results reveal an

255 ancient lineage that began extending its distribution significantly as of the Oligocene (ca. $30 \mathrm{Ma}$;

256 node III; Fig. 2). BioGeoBEARS results show ambiguity in the biogeographic origin of the genus

257 (node I; Fig. 2), but early lineages were distributed in the Southern Hemisphere (areas C, G, I).

258 Results from the BAMM diversification rate through time analysis shows that diversification

259 in Gunnera generally increased over the last ca. 20 Ma (Fig. 3). However, this increase is almost

260 exclusively due to the Pliocene diversification of the Panke clade, when the genus colonized the

261 Andes. This is shown by a significant increase in net diversification rate in the Panke clade,

262 either at its crown (Node VI, probability of 25\%) or at its stem (Node V, probability of $22 \%$ ).

263 The highest rates of diversification were found during the Pleistocene in the Panke clade for the

264 lineage distributed in the northern Andes.

265

266 (c) Climatic niches and history

267 Extant species of Gunnera are inferred to occupy cool (microthermal) and moderate

268 (mesothermal) climatic conditions according to the classification of Nix [48], with a wmean for

269 mean annual temperature (MAT) ranging from $6.4^{\circ}-20.3^{\circ} \mathrm{C}$ and a wmean mean annual

270 precipitation (MAP) ranging from 813 - $3588 \mathrm{~mm}$ (Fig. S2; Table S2). Microthermal species are

271 distributed mainly in temperate latitudes of the Southern Hemisphere, with the exception of $G$.

272 talamancana, which is found at high altitudes (1900-3400 m) in Central America [20].

273 Mesothermal species are distributed in tropical latitudes in South and Central America, Hawaii,

274 New Guinea, and Africa, with the exception of G. arenaria that occurs in temperate areas in

275 New Zealand. 
According to the estimation of ancestral climatic variables, the most recent common

277

278

279

280

281

282

283

284

285

286

287

288

289

290

291

292

293

294

295

296

297

298

ancestor (MRCA) of Gunnera lived under a mesothermal climate sensu Nix (1992), with a MAT of $15.3^{\circ} \mathrm{C}$ and MAP of $1577 \mathrm{~mm}$. Phylogenetic signal using Pagel $\lambda$ was detected for MAT $(\lambda=$ $0.93)$ and mean temperature of coldest quarter $(\mathrm{BIO} 11 ; \lambda=0.92)$ and precipitation of wettest quarter $(\mathrm{BIO} 16 ; \lambda=1)$ and precipitation of warmest quarter $(\mathrm{BIO} 18 ; \lambda=0.93$; Table S3). $w \mathrm{AIC}$ analyses showed that the evolution of the climatic niche is best described by the OU model, suggesting that selection pulls the climatic values toward an optimum. Minimum temperature of coldest month (Bio 6) and mean annual precipitation (Bio 12) showed no difference from a white noise model of evolution, indicating that these variables are independent of phylogenetic relationships in Gunnera species (Table S3).

\section{Discussion}

Based on the divergence times and relationships of the Gunnera multispecies coalescent tree, we examined the contribution of a southern hemisphere taxon to the mega-diverse tropical Andean flora of South America. Our results show the tempo of range expansion and lineage diversification.

\section{(a) Biogeographic history of Gunnera}

A question that has long intrigued biogeographers about widespread southern hemisphere lineages such as Gunnera is whether present-day disjunctions are the result of vicariance or dispersal events. Given the geographically extensive fossil record dating to the Cretaceous [21, 29] and the current distribution in all southern continents except Antarctica [19], Gunnera has 
299 long been considered a typical Gondwanan element [20,49], with vicariance proposed as the

300 main driver of its current geographic distribution [18]. Here we do not find support for

301 unequivocal vicariance events in the biogeographical history of Gunnera, but instead interpret a

302 general pattern of long distance dispersal from our results.

303 The mean crown age of 90 Ma for Gunnera is consistent with previous findings and the

304 variation around the mean age (95\% HPD 165 - $40 \mathrm{Ma}$ ) reflects what has been found in earlier

305 work [50-52]. Gunnera is inferred to have been widespread in the former Gondwanan territories

306 including the southern Andes (area C), southeastern South America (area D), and Africa (area G

307 at Node I in Fig. 2) during the Cretaceous. A Gondwanan distribution is also supported by

308 several fossils from southernmost South America, southwest Africa, the Antarctic Peninsula,

309 Australia, and Tasmania [53]. Gunnera herteri from South America is sister to the remaining

310 Gunnera species, in agreement with previous studies [18, 20, 49], which supports a long history

311 in the southern portions of the continent.

312 A vicariance event could be interpreted at the node where the Australasian lineages (Node II)

313 diverge from the South American and African lineages (Node III), based on the phylogenetic

314 pattern. However, the divergence time for that event dates to the Late Eocene (ca. $40 \mathrm{Ma}$ ) and

315 geological evidence does not support division of these continents at that time [54]. Suitable areas

316 for Gunnera in the tropical latitudes of New Guinea were available when this region emerged

317 above sea level and Australia reached its current latitudinal position, both of which occurred at

318 the end of the Cenozoic [12 Ma; 49]. In agreement with and according to our estimations the

319 tropical lineage G. macrophylla, distributed from the Philippines and Sumatra east to New

320 Guinea and the Solomon Islands, split from the southern Australia and Tasmania lineages at ca.

$32110 \mathrm{Ma}$. This result suggests that the arrival of extant Gunnera in tropical regions (e.g. area $\mathrm{H}$ ) 
322 occurred via long distance dispersal, as has been inferred for other Gondwanan taxa such as

323 Nothofagus [e.g. 55].

324 Another long distance dispersal is inferred at Node III where the African lineage G. perpensa

325 split from rest of the genus at ca. $30 \mathrm{Ma}$, at the time when Africa and South America were

326 completely separated [54]. Node IV joins the Andean species (areas A, B, C) with subgenus

327 Panke (areas A, B, C, D, E, F). Node V infers a colonisation event to Hawaii (area F) and Node

328 VI shows a division between southern South American species (areas B, C, and D) and those

329 from the north of South America and Central America (areas A and E respectively).

330

331 (b) Range expansion in the Andes

332 Gunnera is inferred to have been present in southern South America since the Paleogene (Fig. 2).

333 By the Mid-Miocene the stem node of the Panke clade (15 Ma; Node IV) was distributed in

334 Central America and/or the Andes and began to diversify, both north into Central America and

335 south again into the southern Andes (Fig. 2). The estimated mean age overlaps with that

336 proposed for the formation of the Isthmus of Panama [56], a primarily terrestrial lowland region

337 that has connected North and South America since ca. 15 Ma. Bacon et al. [57] proposed that

338 closure of the isthmus enabled taxa to expand their distributions both north and southwards

339 during pulses of migration (ca. 23, 8, and $5 \mathrm{Ma}$ ). Range expansion at Node IV occurred after a

340 long stasis (ca. $15 \mathrm{Ma}$ ) where there was a dearth of speciation or substantial extinction - two

341 alternative explanations that are generally difficult to distinguish [58].

342 The colonisation of the northern Andes (area A at Node VII, Fig. 2) is inferred to have likely

343 taken place from Central American ancestors, sometime in the Early Pleistocene (ca. 2.27 Ma).

344 Although the Andes began to rise as early as the Early Paleogene [33], it is often difficult to 
345 disentangle the roles of Andean uplift and climate change on Neotropical diversification [but see

34659 ] because they occurred contemporaneously [7]. Gunnera is primarily a wet montane, rather

347 than páramo, lineage, and does not require high elevations for successful dispersal.

349 (C) North American fossils: crown or stem relatives of Panke?

350 A sister relationship between the northernmost species of Gunnera (G. mexicana) and all other 351 species in subgenus Panke, combined with the fact that there are several North American fossil

352 localities from the Late Cretaceous to the Eocene [80-50 Ma; 21], led Wanntorp and Wanntorp

353 (2003) to suggest that the South American species of Panke represented a recolonisation of

354 South America from the north. This result is further supported by morphological similarities of

355 leaf impressions and pollen size between the Late Cretaceous fossils and modern Panke species

$356[21,60]$, and the placement of the Hawaiian species G. petaloidea and G. kauaiensis as the next

357 branching lineage after G. mexicana.

358 This scenario implies that the North American fossils belong to the crown or stem group of

359 Panke, i.e. they would have been derived either from the branch connecting Misandra (G. lobata

360 and G. magellanica) to Panke (Node IV, Fig. 2) or from the branch leading to G. mexicana.

361 Although this is a possible conclusion based on the topology of our Gunnera phylogeny, the

362 divergence times estimated here suggest otherwise. The splits connecting Misandra to the

363 MRCA of Panke (where the dispersal to North America would have taken place) are estimated at

364 ca. $15 \mathrm{Ma}$, which is almost $65 \mathrm{Ma}$ later than the first documented North American fossils. Our

365 results suggest that the North American fossils do not belong to the crown group of Panke.

366 Instead, we suggest they likely represent a lineage that reached North America during the

367 Cretaceous, but did not leave any living descendants. A similar scenario was found in the 
368 inconsistency between DNA-based divergence times and pollen fossils of Nothofagus, where

369 'incongruent' fossils might have been erroneously assigned to crown Nothofagus, whereas they

370 in fact represented extinct stem relatives [55, 61].

371

372 (d) Stasis vs. rapid speciation

373 A remarkable aspect of our results is the striking difference in the stem ages of Gunnera species.

374 Gunnera herteri is inferred to have originated 90 Ma during the Late Cretaceous (Node I),

375 whereas 18 species in the phylogeny are inferred to be younger than $2 \mathrm{Ma}$ (Fig. 2). The contrast

376 between stasis and rapid speciation is also seen in the BAMM results (Fig. 3), where low net

377 diversification rates are shown at ancestral branches and a shift in diversification rate detected in

378 the Andean Panke clade is followed by a steady rate increase (Fig. 3C).

379 It is puzzling why some lineages have experienced long evolutionary stasis, whereas others

380 underwent rapid speciation - all within the genetic constraints of a single clade. Our

381 interpretation of stasis relies on an accurate inference of the dated tree, and wide credible

382 intervals were detected for some nodes. Further, this result could be an artefact of extinction, if

383 the lineages leading to the ancient species in fact diversified but all lineages except one went

384 extinct $[58,62]$. However, there is palaeontological support for these exceptionally old stem

385 ages. Fossil pollen on the Vega Peninsula of Antarctica dated from the Campanian/Late

386 Maastrichtian have a distinctive exine that is nearly indistinguishable from that found in pollen

387 grains of extant species of Australia, New Zealand, and Southeast Asia (Wanntorp et al. 2004).

388 The persistence of Gunnera for a longer time (ca. $90 \mathrm{Ma}$ ) than most other angiosperm genera

389 is remarkable. We interpret our results with caution, but consider them as indicative of strong

390 niche conservatism across the highly disjunct range of Gunnera for wet, montane forest 
391 environments. Indeed, our climatic reconstruction shows a mesothermal niche preference for the

392 crown node of Gunnera (Fig. S2), similar to that identified in other Cretaceous lineages [63].

393 Further, our estimate of phylogenetic signal shows high values (Table S3), particularly those

394 associated with both mean annual and coldest quarter temperature variables, and an Ornstein-

395 Uhlenbeck model, which together indicate that the climatic history of Gunnera underwent

396 selection pressure (e.g. stabilizing selection) that favoured the ancestral niche over time [12].

397 Recently, Hinojosa et al. [55] suggested that lineages of Gondwanan origin expanded into the

398 tropics by tracking mesothermal climates. Dispersal towards current tropical zones has been

399 possible because species have tracked ancestral climatic niches from high or mid-latitudes into

400 lower latitudes, sometimes facilitated by climatic and geological changes.

401 It is interesting that Gunnera, a montane forest clade of Gondwanan origin, successfully

402 dispersed to the northern tropical Andes, where few other similar plant clades could. A key

403 element to this may be due to its colonising nature. Gunnera comprises species of forest edges

404 and marginal habitats [64], appear after landslides in wet forests [Fig. 3C; 65], underwent long

405 distance dispersal events to Hawaiian and the Juan Fernandez Islands, and is persistent in the

406 seed bank [66, 67]. Gunnera species also quickly colonise glacial forelands [68] and their pollen

407 is commonly found in glacial and post-glacial sediments in both southern South America and in

408 Tasmania $[69,70]$. Lastly and potentially most convincingly, the fact that some Gunnera species

409 are invasive $[71,72]$ clearly shows their aggressive colonising abilities that likely differentiate

410 them from other montane plant groups.

411

412 (e) Comparison with other Andean groups 
413 There are multiple examples of plant clades that have colonised the Andes from the north, as we

414 suggest for the Panke clade of Gunnera. Some are 'boreotropical' elements that probably

415 reached South America around the Palaeocene-Eocene Thermal Maximum [ 55 Ma; 73], when a

416 large belt of tropical forest covered much of southern Laurasia, thus functioning as a biotic

417 corridor for Palaeotropical lineages [e.g. 74, 75]. Later, dispersals southwards from North to

418 South America may have been facilitated by the Greater Antilles and the Aves Ridge around the

419 Eocene/Oligocene boundary [76], and finally through the Panama Isthmus after its uplift ca. 15

420 Ma [56]. Examples of northern taxa colonising the Andes with local radiations include

421 Hedyosmum [62, 77] and Lupinus [78]. Many of these northern lineages have undergone

422 significant radiation in the páramo.

423 In contrast, there is relatively little evidence of Andean plant clades that are derived from

424 the south. Some well-known southern Hemisphere ("Gondwana") groups, such as Nothofagus

425 and Araucaria, simply do not enter the Andean tropical zone, but reach tropical areas in

426 Australasia [76]. Fuchsia, which is considered to have a southern origin based on a rich

427 Antarctic Cenozoic fossil record, does not show a clear biogeographic pattern from molecular

428 phylogenies [79]. One robust example is the Andean wax palms, that have moved up the Andean

429 cordilleras from the central portion of the range northwards in a stepping stone fashion

430 [Ceroxylon, see 80 for a review of the pattern].

431

432 5. Conclusions

433 For many decades Gunnera has attracted the attention of botanists and biogeographers concerned

434 with southern hemisphere disjunctions and the break-up of Gondwana. Here we have shown that

435 it also constitutes a model taxon to study biogeography in general, as well as the colonisation and 
436 diversification of southern elements in the tropical Andes in particular. The extraordinary species

437 longevity inferred here for species in Southeast Asia, Africa and eastern Brazil - ca. 90 Ma

438 according to our results - is most likely due to climatic, and potentially morphological,

439 conservatism despite the massive geotectonic and climatic changes that took place during its

440 history. In contrast, the recent and rapid diversification of Andean lineages could be explained by

441 the massive increase in the area of suitable habitats and opportunities for allopatric speciation, as

442 a consequence of the Andean uplift and late Neogene climatic changes. Understanding the

443 evolution of Andean mega-diversity thus requires identifying and tracing the diversification of

444 southern, northern and locally derived taxa.

446 Acknowledgments

447 We would like to thank C. Hughes and U. Swenson for reading and commenting on early

448 versions of the manuscript and S. Razafimandimbison for attempts to sequence ITS for

449 Myrothamnus. We are also thankful to Herbarium GB for allowing us to extract samples for

450 DNA analyses. Vivian Aldén provided laboratory assistance. The analyses were performed on

451 the bioinformatics computer cluster Albiorix at the Department of Biological and Environmental

452 Sciences, University of Gothenburg.

453

454 References

455 1. Myers N., Mittermeier R.A., Mittermeier C.G., da Fonseca G.A.B., Kent J. 2000

456 Biodiversity hotspots for conservation priorities. Nature 403, 853-858.

457 2. Antonelli A., Sanmartín I. 2011 Why are there so many plant species in the Neotropics?

458 Taxon 60, 403-414. 
459 3. Rull V. 2011 Neotropical biodiversity: Timing and potential drivers. Trends in Ecology 460 and Evolution 26(10), 508-513. (doi:10.1016/j.tree.2011.05.011).

461 4. Haffer J. 1969 Speciation in Amazon forest birds. Science 165, 131-137.

462 5. Smith B.T., McCormack J.E., Cuervo A.M., Hickerson M.J., Aleixo A., Cadena C.D., 463 Perez-Eman J., Burney C.W., Xie X., Harvey M.G., Faircloth B.C., Glenn T.C., Derryberry E.P., 464 Prejean J., Fields S., Brumfield R.T. 2014 The drivers of tropical speciation. Nature 515(7527), 465 406-409. (doi:10.1038/nature 13687

466 http://www.nature.com/nature/journal/v515/n7527/abs/nature13687.html - supplementary467 information).

468 6. Dexter K.G., Lavin M., Torke B.M., Twyford A.D., Kursar T.A., Coley P.D., Drake C., 469 Hollands R., Pennington R.T. 2017 Dispersal assembly of rain forest tree communities across the 470 Amazon basin. Proceedings of the National Academy of Sciences 114(10), 2645-2650.

471 7. Gentry A.H. 1982 Neotropical floristic diversity: phytogeographical connections between 472 Central and South America, Pleistocene climatic fluctuations, or an accident of the Andean 473 orogeny? Annals of the Missouri Botanical Garden 69(3), 557-593.

474 8. Luebert F., Weigend M. 2014 Phylogenetic insights into Andean plant diversification. 475 Frontiers in Ecology and Evolution 2. (doi:10.3389/fevo.2014.00027).

$4769 . \quad$ Villagrán C., Hinojosa L.F. 1997 Historia de los bosques del sur de Sudamérica, II: 477 Análisis fitogeográfico. Revista Chilena de Historia Natural 70(2), 1-267.

478 10. Sklenář P., Dušková E., Balslev H. 2011 Tropical and Temperate: Evolutionary History

479 of Páramo Flora. The Botanical Review 77, 71-108. (doi:10.1007/s12229-010-9061-9). 
480 11. Antonelli A., Zizka A., Silvestro D., Scharn R., Cascales-Miñana B., Bacon C.D. 2015

481 An engine for global plant diversity: highest evolutionary turnover and emigration in the

482 American tropics. Frontiers in Genetics 6, e130.

483 12. Wiens J.J., Ackerly D.D., Allen A.P., Anacker B.L., Buckley L.B., Cornell H.V., 484 Damschen E.I., Davies T.J., Grytnes J.A., Harrison S.P., Hawkins B.A., Holt R.D., McCain 485 C.M., Stephens P.R. 2010 Niche conservatism as an emerging principle in ecology and 486 conservation biology. Ecol Lett 13(10), 1310-1324. (doi:Doi 10.1111/J.1461-

487 0248.2010.01515.X).

488 13. Donoghue M.J., Edwards E.J. 2014 Biome shifts and niche evolution in plants. Annual 489 Review of Ecology, Evolution, and Systematics 45, 547-572.

490 14. Crisp M.D., Arroyo M.T., Cook L.G., Gandolfo M.A., Jordan G.J., McGlone M.S., 491 Weston P.H., Westoby M., Wilf P., Linder H.P. 2009 Phylogenetic biome conservatism on a 492 global scale. Nature 458, 754-756.

493 15. Simon M.F., Grether R., de Querioz L.P., Skema C., Pennington R.T., Hughes C.E. 2009 494 Recent assembly of the Cerrado, a neotropical plant divesrity hotspot, by in situ evolution of 495 adaptations to fire. Proceedings of the National Academy of Sciences, USA 106(48), 2035949620364.

497 16. Luteyn J.L. 1999 Páramos: A checklist of plant diversity, geographical distribution, and 498 botanical literature. Memoirs of the New York Botanical Garden 84, 1-278.

499 17. Hooghiemstra H., Wijninga V.M., Cleef A.M. 2006 The paleobotanical record of 500 Colombia: implications for biogeography and biodiversity. Annals of the Missouri Botanical 501 Garden 93, 297-324. 
502 18. Wanntorp L., Wanntorp H.E. 2003 The biogeography of Gunnera L.: Vicariance and

503 dispersal. Journal of Biogeography 30(7), 979-987.

504 19. Bader F.W.J. 1961 Das Areal der Gattung Gunnera L. Botanische Jahrbücher für

505 Systematik, Pflanzengeschichte und Pflanzengeographie 80(3), 281-293.

506 20. Mora-Osejo L.E., Pabón-Mora N., González F. 2011 Gunneraceae. New York, The New

507 York Botanical Garden; 166 p.

508 21. Jarzen D.M. 1980 The occurrence of Gunnera pollen in the fossil record. Biotropica 509 12(2), 117-123.

510 22. Brenner G.J. 1968 Middle Cretaceous spores and pollen from northeastern Peru. Pollen et 511 Spores 10(2), 341-383.

512 23. Oxelman B., Liden M., Berglund D. 1997 Chloroplast rps 16 intron phylogeny of the tribe 513 Sileanae (Caryophyllaceae). Plant Systematics and Evolution 206(1), 393-410.

514 24. Pang X., Liu C., Shi L., Liu R., Liang D., Li H., Chemy S.S., Chen S. 2012 Utility of the 515 trnH-psbA intergenic spacer region and its combinations as plant DNA barcodes: a meta-

516 anlaysis. PLoS ONE 7, e48833. (doi:DOI: 10.1371/journal.pone.0048833).

517 25. Blattner F.R. 1999 Direct amplification of the entire ITS region from poorly preserved 518 plant material using recombinant PCR. BioTechniques 27, 1180-1186.

519 26. Kotting O., Santella D., Edner C., Eicke S., Marthaler T., Gentry M.S., Comparot-Moss 520 S., Chen J., Smith A.M., Steup M., Ritte G., Zeeman S.C. 2009 STARCH-EXCESS4 is a laforin521 like phosphoglucan phosphatase required for starch degredation in Arabidopsis thaliana. The 522 Plant Cell 21(1), 334-346.

523 27. Nylander J.A.A. 2004 MrModeltest v2. Program distributed by the author. Evolutionary 524 Biology Centre, Uppsala University. 
525 28. Jones G., Aydin Z., Oxelman B. 2014 DISSECT: an assignment-free Bayesian discovery

526 method for species delimitation under the multispecies coalecent. Bioinformatics 31(7), 991-998.

527 29. Wanntorp L., Dettmann M.E., Jarzen D.M. 2004 Tracking the Mesozoic distribution of

528 Gunnera: Comparison with the fossil pollen species Tricolpites reticulatus Cookson. Review of

529 Palaeobotany and Palynology 132(3-4), 163-174.

530 30. Matzke N.J. 2014 Model selection in historical biogeography reveals that founder-event 531 speciation is a crucial process in island clades. Systematic Biology 63(6), 951-970.

532 31. Team R.C. 2012 R: A Language and Environment for Statistical Computing. (Vienna,

533 Austria, R Foundation for Statistical Computing.

534 32. Ree R.H., Smith S.A. 2008 Maximum likelihood inference of geographic range evolution

535 by dispersal, local extinction, and cladogenesis. Systematic Biology 57(1), 4-14.

536 33. Garzione C.N., Hoke G.D., Libarkin J.C., Withers S., MacFadden B., Eiler J., Ghosh P., 537 Mulch A. 2008 Rise of the Andes. Science 320(5881), 1304-1307.

538 34. Hoorn C., Wesseling F.P., ter Steege H., Bermudez M.A., Mora A., Sevink J., Sanmartín

539 I., Sanchez-Meseguer A., Anderson C.L., Figuieredo J., Jaramillo C., Riff D., Negri F.R.,

540 Hooghiemstra H., Lundberg J., Stadler T., Särkinen T., Antonelli A. 2010 Amazonia through

541 time: Andean uplift, climate change, landscape evolution and biodiversity. Science 330(6006),

$542 \quad 927-931$.

543 35. Clague D.A., Braga J.C., Bassi D., Fullagar P.D., Renema W., Webster J.M. 2010 The

544 maximum ago of Hawaiian terrestrial lineages: geological constraints from the Koko Seamount.

545 Journal of Biogeography 37(6), 1022-1033.

546 36. McLoughlin S. 2001 The breakup history of Gondwana and its impact on pre-Cenozoic

547 floristic provincialism. Australian Journal of Botany 49(3), 271-300. 
548 37. Rabosky D.L. 2014 Automatic detection of key innovations, rate shifts, and diversity-

549 dependance on phylogenetic trees. PLoS ONE 9(2), e89543.

$55038 . \quad$ Phillips S.J., Anderson R.P., Schapire R.E. 2006 Maximum entropy modeling of species

551 geographic distributions. Ecological Modeling 190, 231-259.

552 39. Hijmans R.J., Cameron S.E., Parra J.L., Jones P.G., Jarvis A. 2005 Very high resolution

553 interpolated climate surfaces for global land areas. Int J Climatol 25(15), 1965-1978. (doi:Doi

554 10.1002/Joc.1276).

555 40. Evans M.E.K., Smith S.A., Flynn R.S., Donoghue M.J. 2009 Climate, niche evolution,

556 and diversification of the "Bird-Cage" evening primroses (Oenothera, sections Anogra and

557 Kleinia). The American Naturalist 173(2), 225-240.

558 41. Heibl C. 2011 PHYLOCLIM: Integrating phylogenetics and climatic niche modelling. (

559 42. Schluter D., Price T., Mooers A.O., Ludwig D. 1997 Likelihood of ancestor states in

560 adaptive radiation. Evolution 51(6), 1699-1711.

561 43. Revell L.J. 2012 Phytools: an R package for phylogenetic comparative biology (and other

562 things). Methods in Ecology and Evolution 3(2), 217-223.

563 44. Pagel M. 1994 Detecting correlated evolution on phylogenies: A general method for the

564 comparative analysis of discrete characters. Proceedings of the Royal Society B: Biological

565 Sciences 255(1342), 37-45.

566 45. Pagel M. 1999 The maximum likelihood approach to reconstructing ancestral character

567 states of discrete characters on phylogenies. Systematic Biology 48(3), 612-622.

568 46. Neyman J., Pearson E.S. 1928 On the use and interpretation of certain test criteria for

569 purposes of statistical inference: Part 1. Biometrika 20A, 175-240. 
570 47. Hansen T.F., Pienaar J., Orzack S.H. 2008 A comparative method for studying adaptation

571 to a randomly evolving environment. Evolution 62(8), 1965-1977. (doi:Doi 10.1111/J.1558-

$572 \quad 5646.2008 .00412 . X)$.

573 48. Nix H. 1991 An environmental analysis of Australian rainforests. In The rainforest

574 legacy, Australian National Rainforest Study Vol 2 (eds. Warren G., Kershaw P.), pp. 1-26.

575 Canberra, Australian Government Publishing Service.

576 49. Fuller D.Q., Hickey L.J. 2005 Systematics and leaf architecture of the Gunneraceae. The

577 Botanical Review 71(3), 295-353.

$57850 . \quad$ Bell C.D., Soltis D.E., Soltis P.S. 2010 The age and diversification of the angiosperms re-

579 revisted. American Journal of Botany 97(8), 1296-1303.

580 51. Magallón S., Gómez-Acevedo S., Sánchez-Reyes L.L., Hernández-Hernández T. 2015 A

581 metacalibrated time-tree documents the early rise of flowering plant phylogenetic diversity. New

582 Phytologist 207(2), 437-453.

583 52. Tank D.C., Eastman J.M., Pennel M.W., Soltis P.S., Soltis D.E., Hinchliff C.E., Brown

584 J.W., Sessa E.B., Harmon L.J. 2015 Nested radiation and the pulse of angiosperm

585 diversification: increased diversification rates often follow whole genome duplications. New

586 Phytologist 207, 454-467.

587 53. Macphail K. 2007 Australian palaeoclimates: Cretaceous to Tertiary: a review of 588 palaeobotanical and related evidence to the year 2000. (Brently, Western Australia, CRC 589 LEME.

590 54. Sanmartín I., Ronquist F. 2004 Southern hemisphere biogeography inferred by event-

591 based models: plant versus animal patterns. Systematic Biology 53(2), 216-243. 
592 55. Hinojosa L.F., Gaxiola A., Perez M.F., Carvajal F., Campano M.F., Quattrocchio M.,

593 Nichida H., Uemura K., Yabe A., Bustamante R., Arroyo M.T.K. 2016 Non-congruent fossil and

594 phylogenetic evidence on the evolution of climatic niche in the Gondwana genus Nothofagus.

595 Journal of Biogeography 43, 555-567.

596 56. Montes C., Cardona A., Jaramillo C.A., Pardo A., Silva J.C., Valencia V., Ayala C.,

597 Perez-Angel L.C., Rodriguez-Parra L.A., Ramirez V., Niño H. 2015 Middle Miocene closure of 598 the Central American Seaway. Science 348(6231), 226-229.

599 57. Bacon C.D., Silvestro D., Jaramillo C.A., Tilston Smith B., Chakrabarty P., Antonelli A. 6002015 Biological evidence supports an early and complex emergence of the Isthmus of Panama.

601 Proceedings of the National Academy of Sciences, USA 112(19), 6110-6115.

602 58. Crisp M.D., Cook L.G. 2009 Explosive radiation or cryptic mass extinction? Interpreting 603 signatures in molecular phylogenies. Evolution 63(9), 2257-2265. (doi:10.1111/j.1558604 5646.2009.00728.x).

605 59. Lagomarsino L.P., Condamine F.L., Antonelli A., Mulch A., Davis C.C. 2016 The abiotic 606 and biotic drivers of rapid diversification in Andean bellflowers (Campanulaceae). New 607 Phytologist 210(4), 1430-1442.

608 60. Wilkinson H.P. 2000 A revision of the anatomy of Gunneraceae. Botanical Journal of the 609 Linnean Society 134(1-2), 233-266.

610 61. Cook L.G., Crisp M.D. 2005 Not so ancient: The extant crown group of Nothofagus

611 represents a post-Gondwanan radiation. Proceedings of the Royal Society B: Biological Sciences 612 272(1580), 2535-2544.

613 62. Antonelli A., Sanmartín I. 2011 Mass extinction, gradual cooling, or rapid radiation?

614 Reconstructing the spatiotemporal evolution of the ancient angiosperm genus Hedyosmum 
615 (Chloranthaceae) using empirical and simulated approaches. Systematic Biology 60(5), 596-615.

616 (doi:10.1093/sysbio/syr062).

617 63. DeConto R.M., Hay W.W., Thompson S.L., Bergengren J. 1999 Late Cretaceous climate

618 and vegetation interactions: cold continental interior paradox. Geological Society of America

619 Special Paper 332, 391-406.

620 64. Greimler J., Lopez-Sepulveda K., Reiter K., Baeza C., Penailillo P., Ruíz E., Navoa P.,

621 Gatica A., Stuessy T.F. 2013 Vegetation of Alejandro Selkirk Islands (Isla Masafuera), Juan

622 Fernandez Archipelago, Chile. Pacific Science 67, 267-282.

623 65. Vanacker V., Vanderschaeghe M., Govers G., Willems E., Poesen J., Deckers J., De

624 Bievre B. 2003 Linking hydrological, infinite slope stability and land-use change models through

625 GIS for assessing the impact of deforestation on slope stability in high Andean watersheds.

626 Geomorphology 52, 299-315.

627 66. Arroyo M.T.K., Cavieres L.A., Humana A.M. 2004 Experimental evidence of potential

628 for persistent seed bank formation at a subantarctic alpine site in Tierra del Fuego, Chile. Annals

629 of the Missouri Botanical Garden 91, 357-365.

630 67. Fesq-Martin M., Friedman A., Peters M., Behrmann J., Kilian R. 2004 Late-glacial and

631 Holocene vegetation history of the Magellanic rain forest in southwestern Patagonia, Chile.

632 Vegetation History and Archaeobotany 13, 249-255.

633 68. Perez C.A., Aravena J.C., Silva W.A., Enriquez K.M., Farina J.M., Armesto J.J. 2014

634 Ecosystem development in short-term postglacial chronosequences: $\mathrm{N}$ and P limitation in glacier

635 forelands from Santa Ines Island, Magellan Strait. Austral Ecology 39, 288-303.

636 69. Heusser C.J., Heusser L.E., Hauser A. 1992 Paleoecology of late Quaternary deposits in

637 Chiloe Continental, Chile. Revista Chilena de Historia Natural 65, 235-245. 
638 70. McKensie G.M., Kershaw A.P. 2000 The last glacial cycle from Wyelangta, the Otway 639 region of Victoria, Australia. Palaeogeography Palaeoclimatology Palaeoecology 155, 177-193.

640 71. Fennell M., Murphy J.E., Gallagher T., Osborne B. 2013 Simulating the effects of 641 climate change on the distribution of an invasive plant, using a high resolution, local scale, 642 mechanistic approach: challenges and insights. Global Change Biology 19, 1262-1274.

643 72. Skeffington M.S., Hall K. 2011 The ecology, distribution and invasiveness of Gunnera L. 644 species in Connemara, Western Ireland. Proceedings of the Royal Irish Academy 111B, 157-175. 645 73. Zachos J.C., Dickens G.R., Zeebe R.E. 2008 An early Cenozoic perspective on 646 greenhouse warming and carbon-cycle dynamics. Nature 451(7176), 279-283.

647 74. Bacon C.D., Baker W.J., Simmons M.P. 2012 Miocene dispersal drives island radiations 648 in the palm tribe Trachycarpeae (Arecaceae). Systematic Biology 61(3), 426-442.

649 75. Antonelli A., Nylander J.A.A., Persson C., Sanmartín I. 2009 Tracing the impact of the 650 Andean uplift on Neotropical plant evolution. Proceedings of the National Academy of Sciences 651 106(24), 9749-9754. (doi:10.1073/pnas.0811421106).

652 76. Iturralde-Vinent M.A., MacPhee R.D.E. 1999 Paleography of the Caribbean region:

653 implication for Cenozoic paleogeography. Bulletin of the American Museum of Natural History 654 238, $1-95$.

655 77. Zhang Q., Feild T.S., Antonelli A. 2015 Assessing the impact of phylogenetic 656 incongruence on taxonomy, floral evolution, biogeographical history, and phylogenetic diversity. 657 American Journal of Botany 102(4), 566-580. (doi:10.3732/ajb.1400527).

658 78. Hughes C., Eastwood R. 2006 Island radiation on a continental scale: Exceptional rates of 659 plant diversification after uplift of the Andes. Proceedings of the National Academy of Sciences 660 of the United States of America 103(27), 10334-10339. 
661 79. Berry P.E., Hahn W.J., Sytsma K.J., Hall J.C., Mast A. 2004 Phylogenetic relationships

662 and biogeography of Fuchsia (Onagraceae) based on noncoding nuclear and chloroplast DNA 663 data. Am J Bot 91(4), 601-614.

664 80. Sanín M.J., Kissling W.D., Bacon C.D., Borchsenius F., Galeano G., Svenning J.-C.,

665 Olivera J., Ramírez R., Trenel P., Pintaud J.-C. 2016 The Neogene rise of the tropical Andes 666 facilitated diversification of wax palms (Ceroxylon: Arecaceae) through geographical 667 colonization and climatic niche separation. Botanical Journal of the Linnean Society 182, 303668317.

669

670 Figures

671 Figure 1. Map of the extant distribution of Gunnera, where high numbers of georeferences are 672 reflected by darker blue colour. The Tricolpites reticulatus pollen fossil was used to calibrate the 673 Gunnera phylogeny in absolute time for this study and is also mapped through major geological 674 time periods. Elevation is shown in grey scale where the lowest and highest global elevations are 675 found in white and black, respectively.

676

677 Figure 2. Biogeographic history based on the BioGeoBEARS optimization of the Gunnera 678 topology calibrated in absolute time using Tricolpites reticulatus pollen (pollen grain shown at 679 the topological placement of the fossil; light microscopy image from Wikicommons). Coloured 680 boxes at the terminals of the phylogeny show the extant geographic distribution of species, with 681 the colour legend defining the areas. All nodes over 0.8 PP are marked and node bars 682 representing the $95 \%$ HPD time interval are shown for nodes of interest. Clades discussed in the 683 text are marked with numerals I-VII. Uncertainty in ancestral range is shown where distributions 
684 with $<5 \%$ probability of occurrence are combined into white portions in pie charts. Inset:

685 Operational areas used: (A) northern Andes; (B) Central Andes; (C) southern Andes; (D)

686 southeastern South America; (E) Central America; (F) Hawaii; (G) Africa; (H) the Malay

687 Archipelago; (I) Tasmania and New Zealand; and other biogeographic areas based on

688 combinations of those defined a priori.

689

690 Figure 3. Diversification rate through time analysis using BAMM for all species sampled within

691 Gunnera. (A) The results show a single, positive diversification rate shift, either at the stem (with

692 0.22 PP) or the crown (with 0.25 PP) node of the Andean Panke clade. (B) Results also support

693 an increase in net diversification rate through time. (C) Some Gunnera species are aggressive

694 colonisers, here showing successful colonisation and persistence in the margins of a landslide in

695 Costa Rica (image from Wikicommons).

696

697 Figure S1. Morphological diversity of Gunnera: A. G. manicata (subgenus Panke), B. G.

698 insignis (subgenus Panke), C. G. perpensa (subgenus Gunnera), D. G. magellanica (subgenus

699 Misandra), E. G. dentata (subgenus Milligania), F. G. herteri (subgenus Ostenigunnera).

700 Photos: A. Antonelli.

701

702 Figure S2. Traitgram of ancestral states of Gunnera climatic niche. Black lines correspond to a

703 projection of the phylogenetic tree in a space defined by the bioclimatic variable mean annual

704 temperature and annual precipitation.

705 


\section{Figure 1}

Map of the extant distribution of Gunnera, where high numbers of georeferences are reflected by darker blue colour.

The Tricolpites reticulatus pollen fossil was used to calibrate the Gunnera phylogeny in absolute time for this study and is also mapped through major geological time periods. Elevation is shown in grey scale where the lowest and highest global elevations are found in white and black, respectively.

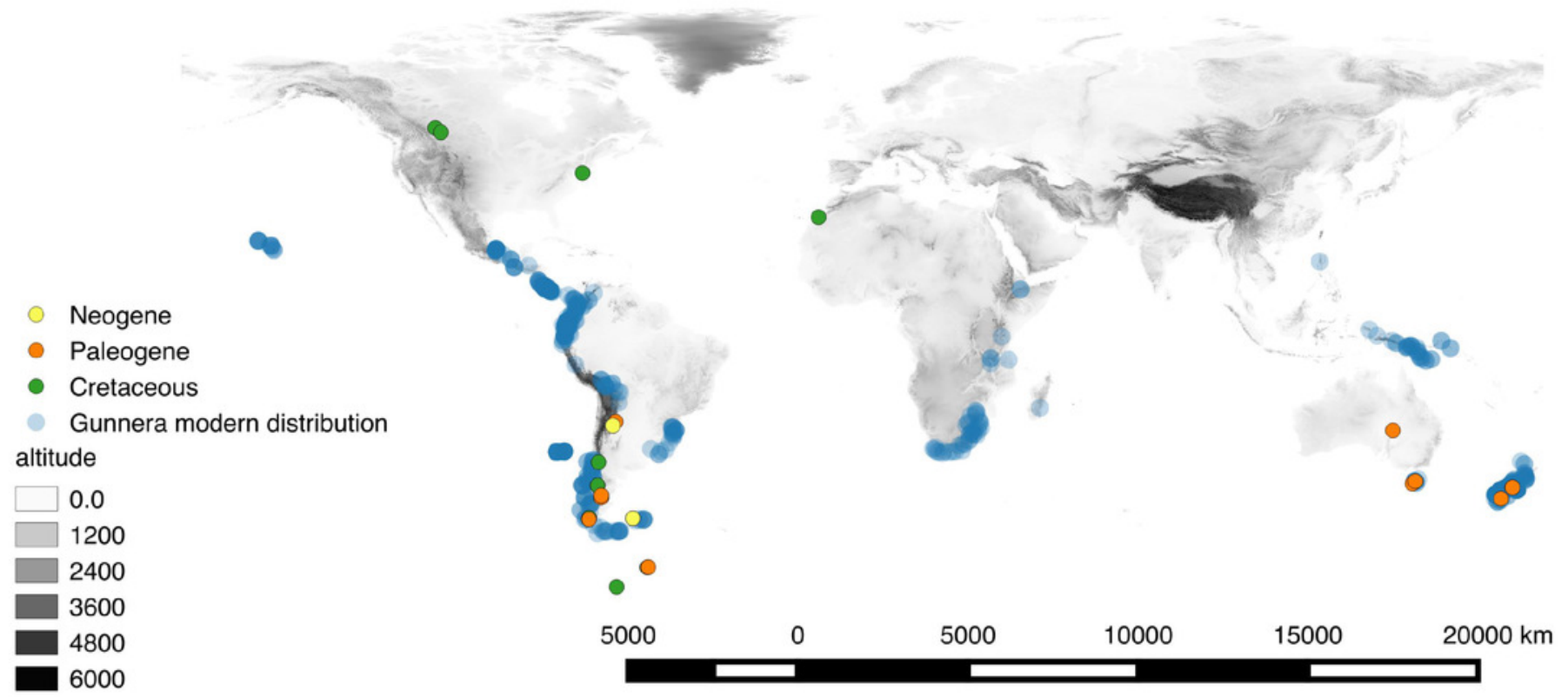




\section{Figure 2}

Biogeographic history based on the BioGeoBEARS optimization of the Gunnera topology calibrated in absolute time using Tricolpites reticulatus pollen.

Coloured boxes at the terminals of the phylogeny show the extant geographic distribution of species, with the colour legend defining the areas. All nodes over 0.8 PP are marked and node bars representing the 95\% HPD time interval are shown for nodes of interest. Clades discussed in the text are marked with numerals I-VII. Uncertainty in ancestral range is shown where distributions with $<5 \%$ probability of occurrence are combined into white portions in pie charts. Inset: Operational areas used: (A) northern Andes; (B) Central Andes; (C) southern Andes; (D) southeastern South America; (E) Central America; (F) Hawaii; (G) Africa; (H) the Malay Archipelago; (I) Tasmania and New Zealand; and other biogeographic areas based on combinations of those defined a priori. 


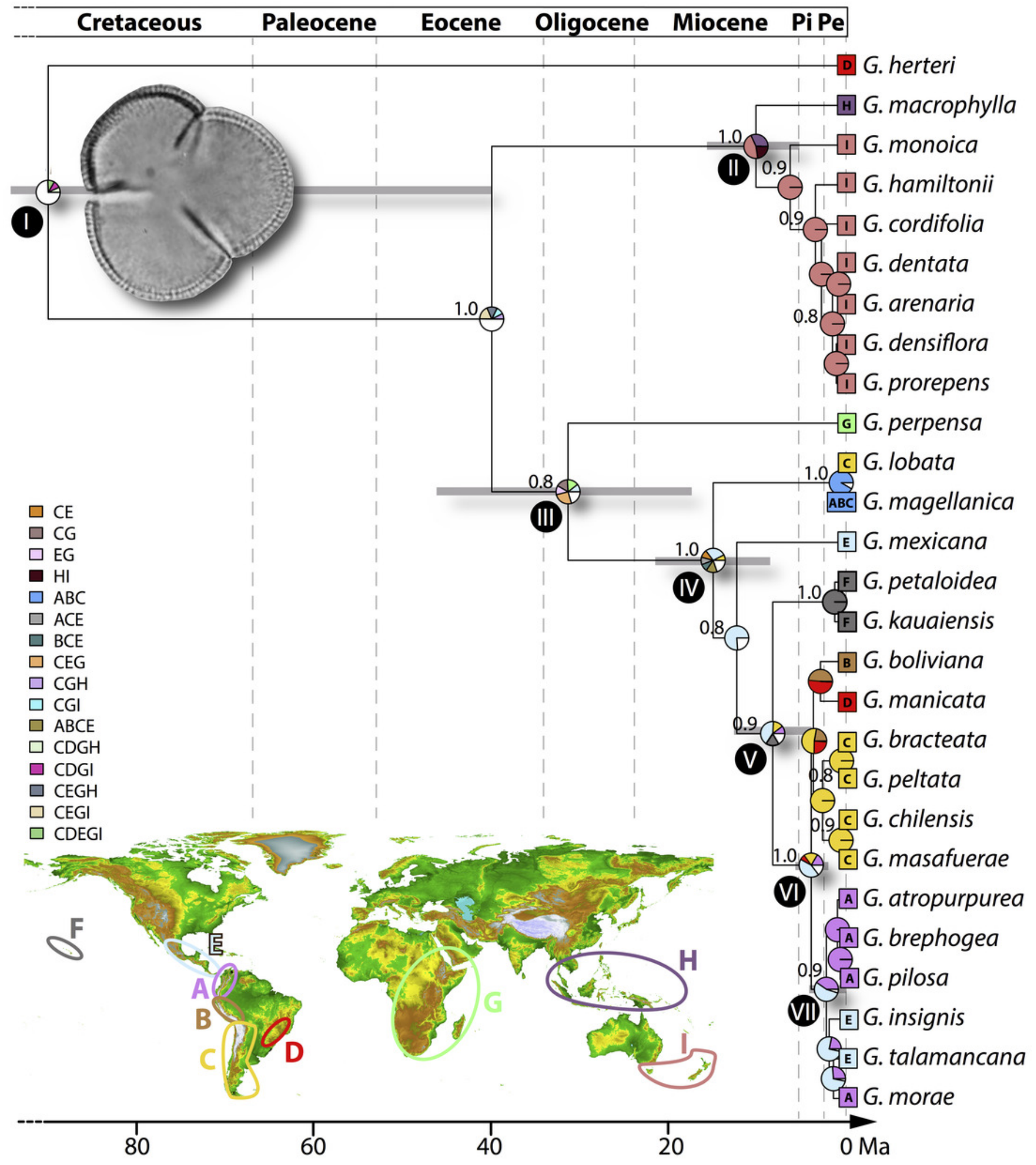




\section{Figure 3}

Diversification rate through time analysis using BAMM for all species sampled within Gunnera.

(A) The results show a single, positive diversification rate shift, either at the stem (with 0.22 PP) or the crown (with 0.25 PP) node of the Andean Panke clade. (B) Results also support an increase in net diversification rate through time. (C) Some Gunnera species are aggressive colonisers, here showing successful colonisation and persistence in the margins of a landslide in Costa Rica (image from Wikicommons). 


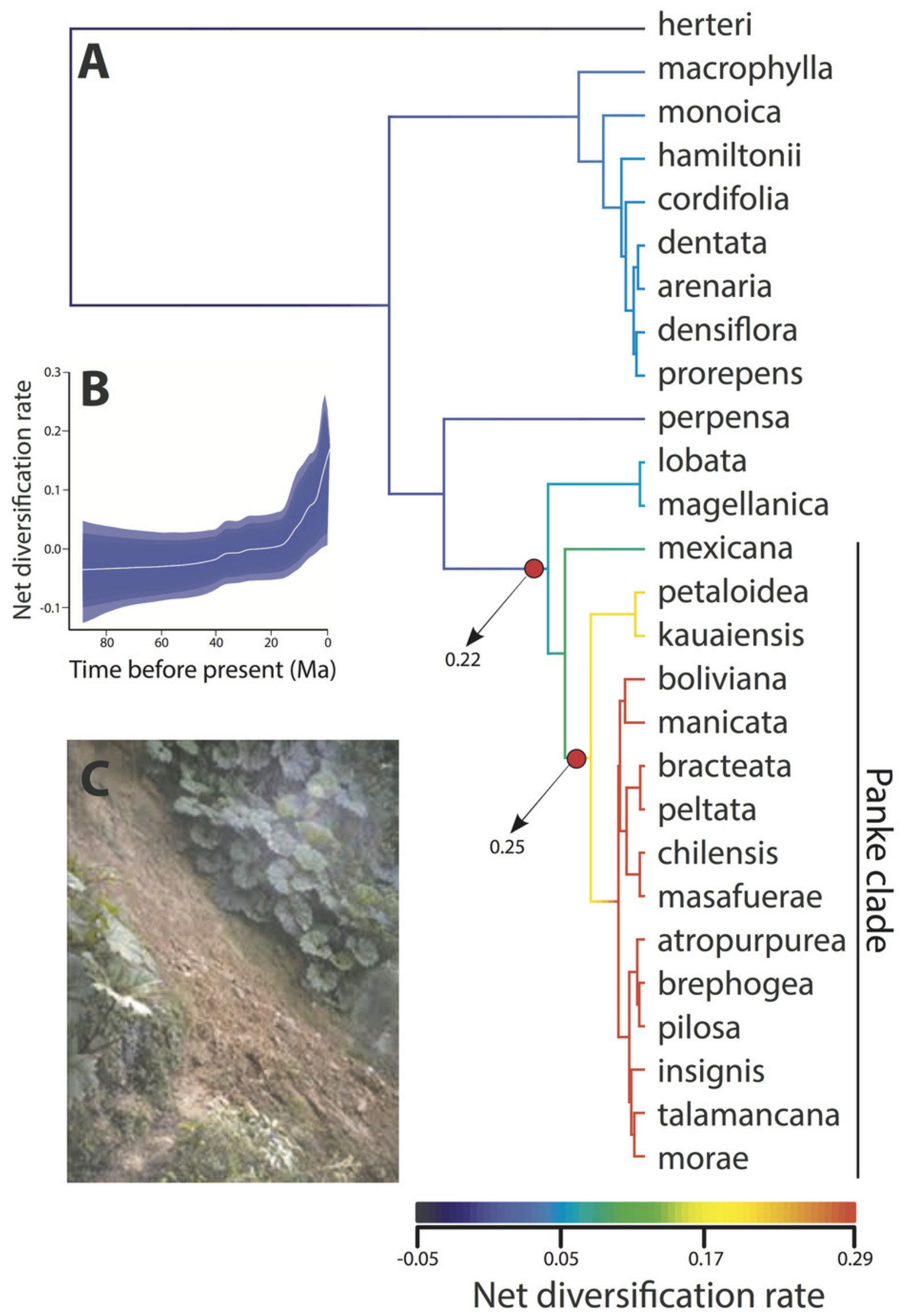

